\title{
Recurrent optic neuritis: clues from a long-term follow up study of recurrent and bilateral optic neuritis patients
}

This article was published in the following Dove Press journal:

Eye and Brain

5 March 2010

Number of times this article has been viewed

\author{
Asli Kurne' \\ Rana Karabudak' \\ Gul Yalcin-Cakmakli' \\ Yasemin Gursoy-Ozdemir \\ Pinar Aydin ${ }^{3}$ \\ Ayse Ilksen-Colpak' \\ Sevda Lule ${ }^{2}$ \\ Tulay Kansu' \\ 'Department of Neurology, \\ ${ }^{2}$ Institute of Neurological Sciences \\ and Psychiatry, Faculty of Medicine, \\ Hacettepe University, Ankara, Turkey \\ ${ }^{3}$ Special Eye Clinic, Ankara, Turkey
}

Background and aim: Optic neuritis $(\mathrm{ON})$ can be recurrent, with unilateral or bilateral presentation. Diagnosis of recurrent cases may be challenging. In this study long-term follow-up of recurrent and/or bilateral $\mathrm{ON}$ patients is reported in an effort to guide differential diagnosis and treatment.

Methods: The study included 474 optic neuropathy patients. Of these, 70 patients with recurrent unilateral or bilateral, and nonrecurrent bilateral $\mathrm{ON}$ were assessed. The characteristics of each ON attack, laboratory and magnetic resonance imaging (MRI) findings, associated diseases and response to treatment were noted for each patient. Most of the patients were reevaluated in the outpatient clinic. Seven patients were investigated for neuromyelitis optica (NMO)immunoglobulin $\mathrm{G}$ ( $\mathrm{IgG}$ ) seropositivity.

Results: Forty-seven patients had recurrent unilateral ON and 23 had bilateral ON. Mean follow-up was 7.55 years. Final diagnoses for recurrent unilateral group were multiple sclerosis (MS) $(n=29)$, chronic relapsing inflammatory optic neuritis (CRION) $(n=11)$, NMO $(n=4)$, or autoimmune thyroid disease $(n=3)$; and for bilateral ON group, MS ( $n=4)$, vasculitis $(n=13)$, postinfectious $\mathrm{ON}(\mathrm{n}=4)$, and sarcoidosis $(\mathrm{n}=2)$. Three patients were positive for NMO antibodies.

Conclusion: Based on the data collected, we conclude when recurrent $\mathrm{ON}$ causes moderate to severe visual loss in the absence of cranial MRI findings typical of MS, other diagnoses should be considered, including NMO.

Keywords: optic neuritis, recurrent, bilateral, multiple sclerosis, neuromyelitis optica

\section{Introduction}

Optic neuritis (ON) is most commonly defined as demyelinating inflammation of the optic nerve. ${ }^{1}$ Loss of vision is accompanied by visual field defects and loss of color vision. Etiological causes of optic neuropathy can be infectious, ischemic, toxic, hereditary, autoimmune, metabolic, infiltrative, or compressive. ${ }^{1}$ In some cases $\mathrm{ON}$ can be recurrent, with unilateral or bilateral presentation. ${ }^{1}$ The diagnosis of recurrent cases may be challenging and accurate prediction of the prognosis depends on correct diagnosis.

The aim of the present study was to determine the clinical features and prognostic factors of the recurrent $\mathrm{ON}$ spectrum. Additionally, we aimed to compare the prognostic factors for differential diagnoses based on the clinical data obtained from our series, with an emphasis on causes other than MS.

\section{Material and methods}

We reviewed the medical records of 474 patients clinically diagnosed with optic neuropathy that were treated in our center between 1985 and 2007. The databases 
of our neuro-ophthalmology and neuro-immunology units were searched for patients with optic neuropathy and data were collected via medical record review, as well as telephone follow-up survey for some patients. Cases with Leber's hereditary optic neuropathy, infiltrative or compressive tumors, and those due to ischemic and toxic causes were excluded. We then focused on 70 cases (59 female, 11 male; age at onset range: 4-45 years) with bilateral and/or unilateral recurrent $\mathrm{ON}$.

The degree of initial visual loss, subsequent visual recovery, accompanying pain, additional neurological symptoms, associated diseases, laboratory findings (including markers for vasculitis and thrombosis), serology for infections, magnetic resonance imaging (MRI) features, types of treatment, and responses to treatment were reviewed. Some of the patients were reassessed in the outpatient clinic. Loss of visual acuity was defined as mild (better than 20/50), moderate (20/50-20/200), and severe (worse than 20/200).

$\mathrm{ON}$ was classified as bilateral (BON) if both eyes were involved simultaneously or sequentially within 3 weeks. BON patients were further divided into recurrent and nonrecurrent groups. Recurrent $\mathrm{ON}$ (RON) was defined as a new unilateral attack occurring after an interval $\geq 4$ weeks. Details of these classifications and subgroups are presented in Figure 1.

These two groups were classified independently according to age at onset, gender, number of recurrences, characteristics of $\mathrm{ON}$, concomitant diseases, laboratory findings, MRI features, follow-up period, and final diagnosis.
Additionally, sera from seven patients with recurrent/ bilateral $\mathrm{ON}$ were studied for NMO-IgG seropositivity with a method described previously by Lennon and colleagues, which is an indirect immunoflourescent detection method. ${ }^{2}$ These labeling studies were performed in the Brain Research Laboratory of the Institute of Neurological Sciences and Psychiatry which is affiliated to Faculty of Medicine, Hacettepe University, Ankara, Turkey. Briefly, mouse brain sections were cut and sera from patients and controls were obtained. After pre-absorption of sera with guinea pig liver powder (self-produced) to reduce nonspecific staining, mouse brain sections were incubated with serum samples as a primary antibody, and immunoreactivity was detected with fluorescein-conjugated goat antibody against human immunoglobulin G (IgG) as a secondary antibody. Sections were mounted and later examined under a fluorescent microscope (Eclipse E600; Nikon, Istanbul, Turkey). Sera from age-matched control subjects $(\mathrm{n}=10)$ and primary antibody omissions were used as negative controls. Specific immunoreactivity to parenchymal vascular brain structures were accepted positive as described by Lennon and colleagues. ${ }^{2}$ The patients were diagnosed with NMO according to Wingerchuk's revised NMO diagnostic criteria. ${ }^{3}$

\section{Results}

In total, 70 out of $474 \mathrm{ON}$ cases $(14.8 \%)$ that met our criteria were included in the study. Among those, 47 patients had RON and 23 had BON (Figure 1). Age at onset was older than 18 years except for seven patients, three from the

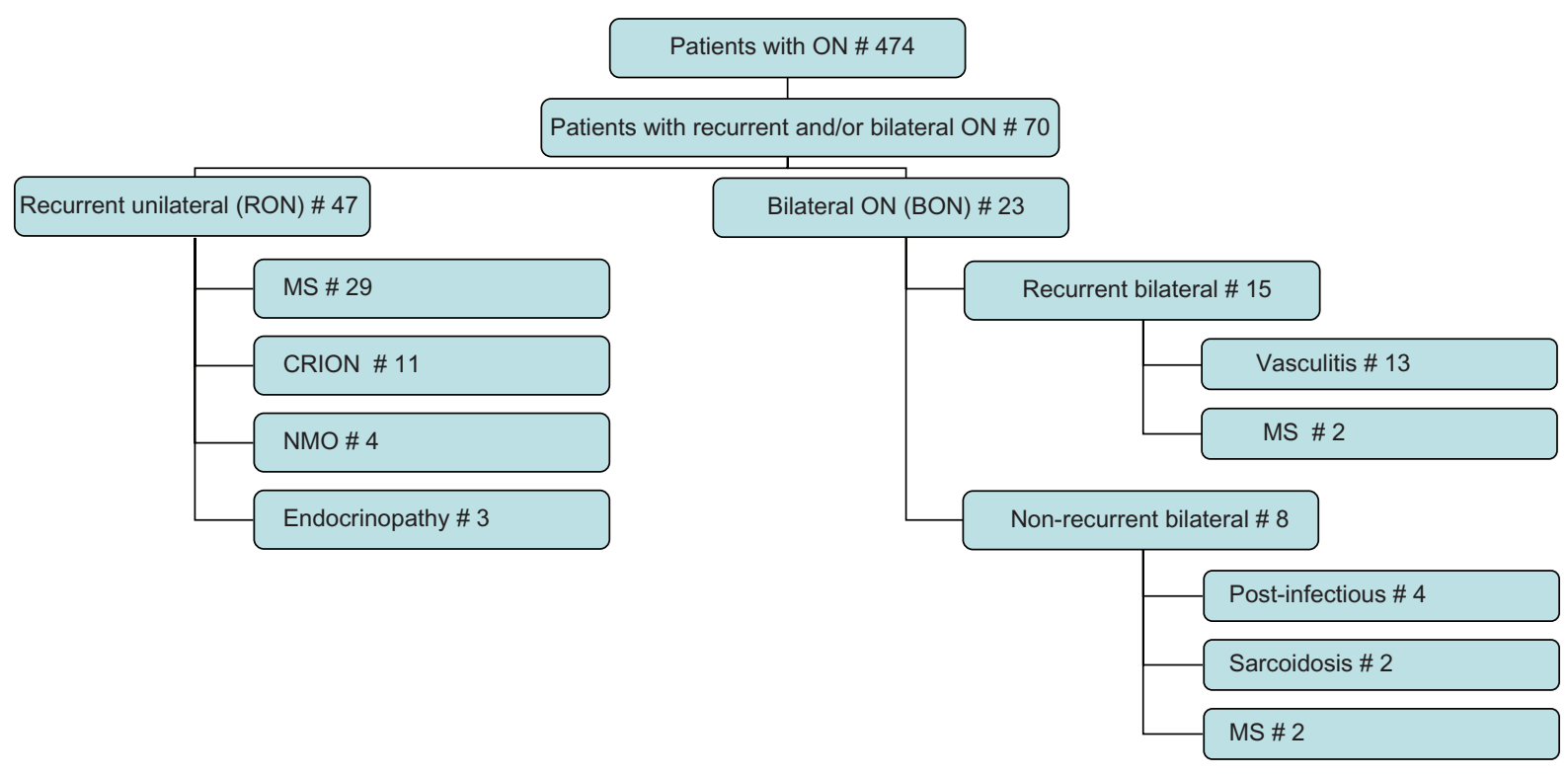

Figure I Overview of subgroups and number of patients classified under each subgroup. 
Table I Characteristics of patients with recurrent unilateral optic neuritis $(n=47)$

\begin{tabular}{llllll}
\hline Diagnosis & $\begin{array}{l}\text { Number and gender } \\
\text { of patients }\end{array}$ & $\begin{array}{l}\text { Age of onset } \\
\text { (mean) }\end{array}$ & $\begin{array}{l}\text { Mean follow up } \\
\text { duration (year) }\end{array}$ & $\begin{array}{l}\text { Mean number } \\
\text { of relapses }\end{array}$ & Visual acuity \\
\hline MS & $22 F, 7 M$ & 26.3 & 9.8 & 2.7 & Mild to severe \\
CRION & $9 F, 2$ M & 30 & 6.14 & 3.8 & $\begin{array}{l}\text { Severe or total loss of } \\
\text { vision at least at one relapse }\end{array}$ \\
NMO & $4 \mathrm{~F}$ & 38 & 7.75 & 3.5 & Severe \\
$\begin{array}{l}\text { Thyroid autoimmune } \\
\text { disease }\end{array}$ & $3 \mathrm{~F}$ & 34 & 4 & 4 & Mild to moderate \\
\hline
\end{tabular}

Abbreviations: MS, multiple sclerosis; CRION, chronic relapsing inflammatory optic neuropathy; F, female; $M$, male.

postinfectious, two from the MS, and two from the vasculitis groups. Age at onset, mean follow-up period, number of relapses, and mean visual acuity loss during each attack are summarized for each group in Tables 1-5. In all the groups the majority of patients were female. ON was the presenting clinical feature in all of the patients.

The RON group included patients that were diagnosed with MS ( $\mathrm{n}=29)$, CRION ( $=11)$, NMO $(\mathrm{n}=4)$, and endocrinopathy $(n=3)$ (Figure 1 and Table 1). Three representative patients with CRION are shown in Table 2. Three patients with CRION were NMO antibody negative. Details of four patients in the NMO group (NMO antibody positive: $\mathrm{n}=3$; NMO antibody negative: $\mathrm{n}=1$ ) are shown in Table 3 . Immunoreactivity was never observed in control serums and primary antibody omission controls, whereas three out of four patients' serum always positively labeled brain parenchymal vasculature similar to aquaporin-4 immunoreactivity described in Lennon's study. ${ }^{2}$

Final diagnoses in the BON group were MS $(n=4)$, vasculitis $(n=13)$, post-infectious $\mathrm{ON}(\mathrm{n}=4)$, and sarcoidosis $(\mathrm{n}=2)$ (Figure 1 and Table 4). Table 5 summarizes the clinical characteristics of three representative patients with the final diagnosis of systemic vasculitis with optic nerve and central nervous system involvement.

\section{Discussion}

Acute idiopathic $\mathrm{ON}$ is the most common cause of optic neuropathy in young adults. It is an isolated inflammatory optic neuropathy secondary to demyelination and is a clinically isolated syndrome suggestive of $\mathrm{MS} ;{ }^{4}$ however, there are several other potential causes of $\mathrm{ON}$, which are fewer in number in cases of recurrent and/or bilateral ON.

MS is one of the major causes of recurrent unilateral ON. ${ }^{5}$ In the present study, both female gender and unilateral onset predominated in the MS group, as expected. Only four patients, who were ultimately diagnosed with MS, experienced bilateral simultaneous ON. In the recurrent unilateral ON group, attacks were accompanied by pain with eye movement $(60 \%)$. In the Optic Neuritis Treatment Trial (ONTT) ocular or periorbital pain was reported in $92 \%$ of the cases, of which $87 \%$ were associated with exacerbation of pain with eye movement. ${ }^{6}$ Although the majority of cases in the present study experienced pain with eye movement, the absence of pain did not exclude the diagnosis of ON. Visual loss at presentation was mild to moderate in our MS group; however, 14 patients experienced severe visual loss at least once but then recovered. Most patients had complete recovery during follow-up. On the other hand, among the patients in the bilateral ON group that were diagnosed with MS, recovery was limited and occurred later, as compared to those in the unilateral ON group. Another noteworthy observation was the short time interval between attacks and the significantly higher frequency of attacks during the first 2 years following onset in the unilateral group ( 56 of 78 ON attacks (71.8\%) in total took place in the first 2 years).

The term CRION was first used by Kidd and colleagues to describe a form of inflammatory optic neuropathy characterized by relapses and remissions in patients with normal brain MRI results. ${ }^{7}$ In all, 11 of our patients fit this description,

Table 2 Three representative patients with chronic relapsing inflammatory optic neuropathy (CRION)

\begin{tabular}{llllllll}
\hline $\begin{array}{l}\text { Sex/age } \\
\text { of onset }\end{array}$ & $\begin{array}{l}\text { No. of ON } \\
\text { attacks }\end{array}$ & $\begin{array}{l}\text { Time interval between } \\
\text { relapses (6 w-5 } \text { y) }\end{array}$ & Pain & $\begin{array}{l}\text { Last visual } \\
\text { acuity }\end{array}$ & NMO-IgG & $\begin{array}{l}\text { Response to } \\
\text { corticosteroids }\end{array}$ & $\begin{array}{l}\text { Current } \\
\text { treatment }\end{array}$ \\
\hline F/30 & 3 & $3 \mathrm{y} / 5 \mathrm{y}$ & + & R: total loss L: 20/200 & - & + & Corticosteroids \\
$\mathrm{F} / 26$ & 6 & $4 \mathrm{~m} / 2 \mathrm{~m} / 4 \mathrm{~m} / 4 \mathrm{~m} / 2 \mathrm{~m}$ & + & R: $20 / 20 \mathrm{~L}: 20 / 30$ & - & +/steroid dependency & $\begin{array}{l}\text { Azathioprine } \\
\text { M/25 }\end{array}$ \\
\hline
\end{tabular}

Abbreviations: F, female; M, male; w, week; m, month; y, year; lgG, immunoglobulin G; N/A, not available; R, right; L, left. 
Table 3 Patients with the diagnosis of neuromyelitis optica (NMO) $(n=4)$

\begin{tabular}{|c|c|c|c|c|c|c|c|}
\hline $\begin{array}{l}\text { Sex/age } \\
\text { of onset }\end{array}$ & $\begin{array}{l}\text { Number of } \\
\text { ON attacks }\end{array}$ & $\begin{array}{l}\text { Number of } \\
\text { spinal cord } \\
\text { attacks }\end{array}$ & $\begin{array}{l}\text { Sequence } \\
\text { of attacks }\end{array}$ & $\begin{array}{l}\text { Lab findings, } \\
\text { VEP, MRI }\end{array}$ & NMO-IgG & $\begin{array}{l}\text { Follow-up } \\
\text { duration } \\
\text { (year) }\end{array}$ & Outcome \\
\hline $\mathrm{F} / 45$ & 4 unilat & 6 & $\begin{array}{l}\text { ON/ON/ON + TM/ } \\
\text { TM/TM/TM/ } \\
\text { ON + TM/ON + TM }\end{array}$ & $\begin{array}{l}\text { ANA: I/320 Brain MRI: N, spinal } \\
\text { MRI: long segment cervico- } \\
\text { thoracal lesions }\end{array}$ & -* & 8 & $\begin{array}{l}\text { R: light perception, } \\
\text { L: } 20 / 400 \text {, paraplegia }\end{array}$ \\
\hline$F / 43$ & 3 unilat & None & $\begin{array}{l}\text { Left ON/Right ON/ } \\
\text { Right ON }\end{array}$ & $\begin{array}{l}\text { VEP: R: delayed latency, L: no } \\
\text { response Brain MRI: N }\end{array}$ & + & 7 & $\begin{array}{l}\text { R: } 20 / 20 \text {, L: light } \\
\text { perception }\end{array}$ \\
\hline $\mathrm{F} / 4 \mathrm{I}$ & 4 unilat & None & $\begin{array}{l}\text { Left ON/Right ON/ } \\
\text { Right ON/Right ON }\end{array}$ & ANA: $1 / 80$ & + & 2 & R: 20/400, L: 20/20 \\
\hline$F / 23$ & 2 unilat & 2 & $\begin{array}{l}\text { Left ON/Left ON/ } \\
\text { TM/TM }\end{array}$ & $\begin{array}{l}\text { ANA: I/80 VEP: R: N, L: delayed } \\
\text { latency Brain MRI:N, spinal MRI: } \\
\text { long segment thoracal lesions }\end{array}$ & + & 14 & $\begin{array}{l}\mathrm{R}: 20 / 20, \mathrm{~L}: 20 / 30 \text {, } \\
\text { paraparesis }\end{array}$ \\
\hline
\end{tabular}

*Sample was taken under azathioprine therapy.

Abbreviations: F, female; ON, optic neuritis; BON, bilateral ON;TM, transverse myelitis;VEP, visual evoked potentials; MRI, magnetic resonance imaging; ANA, anti-nuclear antibody; N, normal; R, right; L, left.

as vasculitis and endocrinopathy were ruled out. This group was composed of young females with recurrent unilateral $\mathrm{ON}$ attacks. In Table 2 features of three representative patients are given. Both cranial MRI and cerebrospinal fluid examinations were normal, and the oligoclonal band was negative in all of our patients. The number of relapses was higher in the CRION group than in the MS group and the patients in the CRION group had severe or total loss of vision during at least one relapse. The time interval between attacks was variable. During follow-up none of the patients experienced a myelitis attack. Response to corticosteroids was not always favorable and corticosteroid dependency developed in some patients, as previously reported. ${ }^{7}$ Immunosuppressive therapy was the treatment of choice for our CRION group. The classification of this group is difficult and necessitates exclusion of other possible causes. Three patients from this group were tested for the presence of NMO antibodies in their serum during follow-up and the results were negative (Table 2).

Recent reports focus on NMO antibody-positive recurrent ON without clear evidence of transverse myelitis. ${ }^{8-11}$ The typical clinical manifestations of NMO are recurrent ON, long segment longitudinal transverse myelitis, or both; however, some cases are not compatible with this classical definition. Dinkin and colleagues reported three cases that had isolated recurrent $\mathrm{ON}$ or chiasmitis that were $\mathrm{NMO}$ antibody-positive. ${ }^{8}$ Two of our NMO patients had only relapses of ON without any transverse myelitis (TM). The follow-up periods for these two patients were 7 and 2 years, respectively, and the possibility of future TM attacks cannot be ruled out. Matiello and colleagues reported that six of 12 patients $(50 \%)$ that presented with recurrent $\mathrm{ON}$ and tested positive for NMO-IgG had an episode of myelitis and fulfilled the diagnostic criteria for NMO after a median follow-up of 8.4 years. ${ }^{10}$ Finally, the serology for NMO antibodies was positive in these patients. NMO seropositive patients are reported to have a poorer vision outcome when compared to seronegative patients. ${ }^{10}$

All of our NMO patients had normal cranial MRI results and all had relapsing NMO. Among the four patients that met the criteria for $\mathrm{NMO}$, three were positive for NMO antibodies in their serum. The absence of antibodies in the first patient in Table 3 was thought to be due to long-term azathioprine treatment. The clinical presentation of this patient was typical of NMO. Laboratory examination and cranial and spinal MRIs were helpful for diagnosis, as well as the clinical follow-up. Immunosuppressive therapy is the treatment of choice for such patients.

Among the patients in the present study, three had recurrent $\mathrm{ON}$ and thyroid autoimmune disease (Graves' disease,

Table 4 Patients who developed bilateral simultaneous optic neuritis $(n=23)$

\begin{tabular}{llllll}
\hline Diagnosis & $\begin{array}{l}\text { Number and gender } \\
\text { of patients }\end{array}$ & $\begin{array}{l}\text { Age of onset } \\
\text { (mean) }\end{array}$ & $\begin{array}{l}\text { Mean follow up } \\
\text { duration (year) }\end{array}$ & $\begin{array}{l}\text { Mean number } \\
\text { of relapses }\end{array}$ & Visual acuity \\
\hline MS & 4F & 27 & 8.25 & 1.25 & Moderate loss \\
Vasculitis & I3F & 28 & 6 & 6.37 & Severe or total loss of vision \\
Post-infectious ON & 3F, IM & 22 & 6 & 1 & Moderate to severe \\
Sarcoidosis & IF, IM & 25 & I & I & Severe \\
\hline
\end{tabular}

Abbreviations: MS, multiple sclerosis; NMO, neuromyelitis optica; F, female; M, male. 
Table 5 Clinical characteristics of three representative patients with the final diagnosis of systemic vasculitis with optic nerve and central nervous system involvement

\begin{tabular}{|c|c|c|c|c|c|c|}
\hline $\begin{array}{l}\text { Sex/age } \\
\text { of onset }\end{array}$ & $\begin{array}{l}\text { Clinical } \\
\text { presentation }\end{array}$ & $\begin{array}{l}\text { Systemic } \\
\text { symptoms }\end{array}$ & $\begin{array}{l}\text { Laboratory } \\
\text { findings }\end{array}$ & $\begin{array}{l}\text { Disease coursel } \\
\text { Follow-up } \\
\text { duration (year) }\end{array}$ & Outcome & Diagnosis \\
\hline$F / 2 I$ & $\begin{array}{l}\text { Recurrent optic } \\
\text { neuropathy }\end{array}$ & $\begin{array}{l}\text { Arthritis, arthralgia, } \\
\text { dry mouth and eyes }\end{array}$ & $\begin{array}{l}\text { ANA (+), anti-dsDNA } \\
(+), \text { ENA }(+), \text { APL }(-)\end{array}$ & $\mathrm{RR} / \mathrm{I} 4$ & Left optic atrophy & SLE \\
\hline$F / 34$ & $\begin{array}{l}\text { Recurrent optic } \\
\text { neuropathy, } \\
\text { hemiparesis }\end{array}$ & Arthralgia & $\begin{array}{l}\text { ANA }(+), \text { anti-dsDNA }(+) \\
\text { ENA }(-), \text { APL }(-)\end{array}$ & $\mathrm{RR} / 4.5$ & Mild hemiparesis & SLE \\
\hline $\mathrm{F} / \mathrm{II}$ & $\begin{array}{l}\text { Recurrent optic } \\
\text { neuropathy, } \\
\text { transverse } \\
\text { myelopathy }\end{array}$ & $\begin{array}{l}\text { Oral aphthous lesion } \\
\text { Schimmer (+) Salivary } \\
\text { gland biopsy }(+)\end{array}$ & $\begin{array}{l}\text { ENA SSa (+), APL, ACL }(-) \text {, } \\
\text { ANA }(-) \text {, anti-dsDNA (-) }\end{array}$ & $\mathrm{RR} / \mathrm{I5}$ & $\begin{array}{l}\text { Paraparesis, severe } \\
\text { bilateral visual loss } \\
\text { (counting fingers at } \\
\text { I meter) }\end{array}$ & $\begin{array}{l}\text { Sjögren's } \\
\text { syndrome }\end{array}$ \\
\hline
\end{tabular}

Abbreviations: F, female; ANA, anti-nuclear antibody; ds-DNA, double strand deoxyribonucleic acid; ENA, extractable nuclear antigen; APL, anti-phospholipid; ACL, anticardiolipin; RR, relapsing remitting; SLE, systemic lupus erythematosus.

$\mathrm{n}=1$; Hashimoto's thyroiditis, $\mathrm{n}=2$ ) (Table 1). These patients also had other laboratory test and cranial MRI results that were negative. As no potential causes other than thyroid autoimmune disease were noted, despite detailed examinations, we considered the possibility that recurrent $\mathrm{ON}$ may have been related to thyroid dysfunction. A possible association between endocrinopathy and recurrent $\mathrm{ON}$ has been reported. ${ }^{12,13}$ These cases with stereotypical involvement of the optic nerves and spinal cord had amenorrhea and galactorrhea, and/or as in our cases, thyroid dysfunction.

Clinical characteristics of three representative patients in the present study that presented with $\mathrm{ON}$ and had a final diagnosis of systemic vasculitis are summarized in Table 5 . This group of 13 patients included those with systemic lupus erythematosus (with or without anti-phospholipid syndrome), Sjögren's syndrome, and polyarteritis nodosa. ON can be a rare presenting feature of primary Sjögren's syndrome and systemic lupus erythematosus (SLE), and can occur before or at the time of diagnosis. ${ }^{14,15} \mathrm{ON}$ associated with SLE is often painless, subacute, and progressive, and is commonly very severe. ${ }^{16}$ Our patients with SLE experienced recurrent severe unilateral or bilateral ON with loss of visual acuity worse than 20/400. Mean number of ON attacks was highest in the vasculitis group. Additional neurological and systemic symptoms and signs were observed during follow-up. Laboratory tests as well as brain and spinal cord MRI aided final diagnosis. Response to corticosteroid therapy was limited, and aggressive immunosuppressive treatment was required to control the disease process.

In the post-infectious $\mathrm{ON}$ group three of the four patients were 4-15 years old and onset was acute; two of the patients had a history of viral infection (infectious mononucleosis, $\mathrm{n}=1$; measles immunization preceding the attack, $\mathrm{n}=1$ ). They all recovered well and no recurrence was noted.
For the patients with a final diagnosis of sarcoidosis, brain MRI and serum angiotensin-converting enzyme levels aided the diagnosis. Loss of visual acuity was severe, but response to corticosteroid treatment was good and no recurrence was noted during the following year.

The present study was based on long-term follow-up and summarized the clinical features of a distinct group of patients. Based on the data collected, we propose that recurrent $\mathrm{ON}$ that causes moderate to severe visual loss without any cranial MRI findings typical of MS should be suspected for other diagnoses, including NMO. Early diagnosis and immunosuppressive treatment will help prevent persistent disability. We suggest that patients with RON or BON that have normal MRI results be investigated for the presence of other autoimmune diseases, thyroid autoimmune disease, and NMO antibodies; these patients should be followed closely for the possible development of demyelinating disease.

\section{Disclosures}

The authors report no conflicts of interest in this work.

\section{References}

1. Zeid NA, Bhatti MT. Acute inflammatory demyelinating optic neuritis: evidence-based visual and neurological considerations. Neurologist. 2008;14:207-223.

2. Lennon VA, Wingerchuk DM, Kryzer TJ, et al. A serum autoantibody marker of neuromyelitis optica: distinction from multiple sclerosis. Lancet. 2004;364:2106-2112.

3. Wingerchuk DM. Diagnosis and treatment of neuromyelitis optica. Neurologist. 2007;13:2-11.

4. Murphy MA. Clinical update on optic neuritis and multiple sclerosis. Med Health R I. 2008;91:57-59.

5. Nilsson P, Larsson EM, Maly-Sundgren P, Perfekt R, SandbergWollheim M. Predicting the outcome of optic neuritis: evaluation of risk factors after 30 years of follow-up. J Neurol. 2005;252:396-402.

6. Optic Neuritis Study Group. The clinical profile of optic neuritis Experience of the Optic Neuritis Treatment Trial. Arch Ophthalmol. 1991;109:1673-1678. 
7. Kidd D, Burton B, Plant GT, Graham EM. Chronic relapsing inflammatory optic neuropathy. Brain. 2003;126:276-284.

8. Dinkin MJ, Cestari DM, Stein MC, Brass SD, Lessel S. NMO antibody positive recurrent optic neuritis without clear evidence of transverse myelitis. Arch Ophthalmol. 2008;126:566-570.

9. Giovannoni G. To test or not to test: NMO-IgG and optic neuritis. Neurology. 2008;70:2192-2193.

10. Matiello M, Lennon VA, Jacob A, et al. NMO-IgG predicts the outcome of recurrent optic neuritis. Neurology. 2008;70:2197-2200.

11. De Sèze J, Arndt C, Jeanjean L, et al. Relapsing inflammatory optic neuritis: is it neuromyelitis optica? Neurology. 2008;70:2075-2076.

12. Vernant JC, Cabre P, Smadja D, et al. Recurrent optic neuromyelitis with endocrinopathies: a new syndrome. Neurology. 1997;48:58-64.
13. Petravic D, Habek M, Supe S, Brinar VV. Recurrent optic neuromyelitis with endocrinopathies: a new syndrome or just a coincidence? Mult Scler. 2006;12:670-673.

14. Siatkowski RM, Scott IU, Verm AM, et al. Optic neuropathy and chiasmopathy in the diagnosis of systemic lupus erythematosus. J Neuroophthalmol. 2001;21:193-198.

15. Wise CM, Agudelo CA. Optic neuropathy as an initial manifestation of Sjogren's syndrome. J Rheumatol. 1988;15:799-802.

16. Scolding $\mathrm{N}$. The differential diagnosis of multiple sclerosis. $J$ Neurol Neurosurg Psychiatry. 2001;71(Suppl 2:ii):9-15.
Eye and Brain

\section{Publish your work in this journal}

Eye and Brain is an international, peer-reviewed, open access journal focusing on clinical and experimental research in the field of neuroophthalmology. All aspects of patient care are addressed within the journal as well as basic research. Papers covering original research, basic science, clinical and epidemiological studies, reviews and evaluations,

\section{Dovepress}

guidelines, expert opinion and commentary, case reports and extended reports are welcome. The manuscript management system is completely online and includes a very quick and fair peer-review system, which is all easy to use. Visit http://www.dovepress.com/testimonials.php to read real quotes from published authors. 